\title{
Power generating units for a powered roof support complex
}

\author{
Dawid Szurgacz ${ }^{1 *}$, Krzysztof $\operatorname{Kos}^{1}$, Patryk Szolc ${ }^{1}$, Tatiana Gvozdkova ${ }^{2}$ \\ ${ }^{1}$ Polska Grupa Górnicza S.A., KWK ROW ruch Chwałowice, ul. Przewozowa 4, 44-206 Rybnik, \\ Poland \\ ${ }^{2}$ Kuzbass State Technical University, Mezhdurechensk branch, 652881, Stroitelei Avenue, 36, \\ Mezhdurechensk, Russia
}

\begin{abstract}
The degree of utilisation of machinery and equipment is an important factor influencing the volume of daily output of an underground hard coal mine. Consequently, it also affects the efficiency and economic performance of an underground mining plant. The main task of a new pumping station is to ensure safety and continuity of the operation process in both active and new longwalls in the future. The article presents a modern and innovative pumping station that meets the assumptions of Industry 4.0. The power units supplying a longwall complex included in the central pumping station were selected so as to minimise the number of failures. The interruptions in the technological process of coal mining related to the lack or insufficient pressure of the working medium in the supply bus of the powered roof support are caused by inadequate type of hydraulic pumps. The paper presents a developed concept of an innovative central hydraulic pumping station feeding a longwall complex based on a powered roof support. The presented implementation-starting from the concept through design and implementation-has contributed to the improvement of working conditions and safety.
\end{abstract}

\section{Introduction}

The increase in demand for electricity from coal or lignite is still visible worldwide $[3,5]$. To ensure that the global coal extraction stays at the same, high level in the next 25 years is a challenge for the entire mining industry and each facility connected to it $[6,15]$. Maintaining stability requires innovative technologies to be adapted today [7], continuous research and new solutions. The world's hard coal mining is currently dominated by China and Russia, with their level of natural hazards differing from those in Poland [9]. Poland, among the world's leading companies, has the greatest experience of mining in areas characterised by natural hazards [1]. The increase in natural hazards is related to the increase in the depth of exploitation $[11,13]$. One of the main threats is methane $[14,2]$, which is mainly influenced by the depth of the deposited seams [12]. From a technical point of view, the increased depth of operation requires the use of a powered roof support with greater load-bearing capacity [4]. Increasing the pitch of the roof support results in using more steel. Due to the greater depth of extraction and the increase in natural hazards,

\footnotetext{
*Corresponding author: dawidszurgacz@vp.pl
} 
extraction costs are rising. This in turn results in a decrease in the economic efficiency of Polish mines, and thus also in a decrease in the competitiveness of Polish coal on the global market. In the near future, it will be important for the profitability of the Polish coal mining industry to increase extraction and productivity in order to achieve the so-called economies of scale. There are only two factors that can improve the efficiency of a mine. The first is to extent the availability of machines and equipment located in the longwall excavation. This can be achieved by a rational way of transporting the miners to the work area or by using appropriate working time. The second way includes measure such as increasing the utilisation rate of availability, reducing downtime and failures through innovative and improving reliability of machines and work organisation. Polska Grupa Górnicza S.A. together with the engineers of the KWK ROW Chwałowice mine developed a concept of an innovative central hydraulic pumping station on the basis of the adopted program of Industry 4.0. The developed concept was the foundation of the project which was later successfully implemented [8]. The construction of the innovative central hydraulic pumping station resulted from the need to implement the latter method to increase the efficiency of the plant. This is also aimed at reducing the number of failures and stoppages in terms of hydraulic power supply to the powered roof support. These failures make it impossible to move the section of the powered roof support into a new position and to obtain required initial support. Correct conditions of hydraulic supply of powered roof supports are one of the factors ensuring safe and undisturbed process of hard coal mining in a longwall system $[10]$.

\section{Methodology of research}

The primary objective of the concept and assumptions for design of the central hydraulic pumping station was to find a method that will make it possible to power the powered roof support of each longwall in a given mine from one place. The analysis showed that it was necessary to build long pipelines in order to deliver the oil-water emulsion to the extraction areas under appropriate pressure. The pipelines, however, should be as short as possible due to the need to minimise the pressure losses associated with fluid flow resistance in the hydraulic line. Therefore, the location of the pumping station must take into account both factors. It should be close to the mine's central point - a shaft. Hence the central hydraulic pumping station in KWK ROW Chwałowice is located near the shaft. This brings a number of benefits such as:

- limited the access of dusty air to technical equipment, which has a positive effect on the purity of the oil and water emulsion,

- equal quality of the emulsion in all longwalls as it is impossible to add water from fire pipes to the tank at times of increased demand,

- no need to relocate the hydraulic power generating unit and related works in terms of preparing the place of their use,

- the proximity of the workshop where the spare parts are located, which makes all repairs faster,

- continuous monitoring of the pumps by a properly trained operator,

- no possibility of third parties to interfere with the operator's power generating unit.

Figure 1 shows a concept design of a central hydraulic pumping station. It includes such components as tanks, filters, collectors or feeding pumps. The oil-water emulsion first flows through the inflow pipeline 13 and discharge pipe 14 and goes to the tank 1 , then flows from the tank via the suction manifold 2 and goes to the feeding pump 3 . The pumps pump the liquid through a discharge manifold 4 to low-pressure filters 5 . The filtered emulsion flows through the feeding manifold 6 to the tanks, then it is transferred to highpressure pumps 8 via suction manifold 7 . The pumps pump the emulsion into the pressure 
manifold 9 and then it is filtered again under pressure in the high-pressure filter station 10 . From the filter station it goes to the next pressure collector 11, from where it is separated into three DN80 pressure pipes running to the individual extraction areas.

Figure 2 shows the adopted scheme based on which the executive design was developed.

Figures and tables, as originals of good quality and well contrasted, are to be in their final form, ready for reproduction, pasted in the appropriate place in the text. Try to ensure that the size of the text in your figures is approximately the same size as the main text (10 point). Try to ensure that lines are no thinner than 0.25 point.

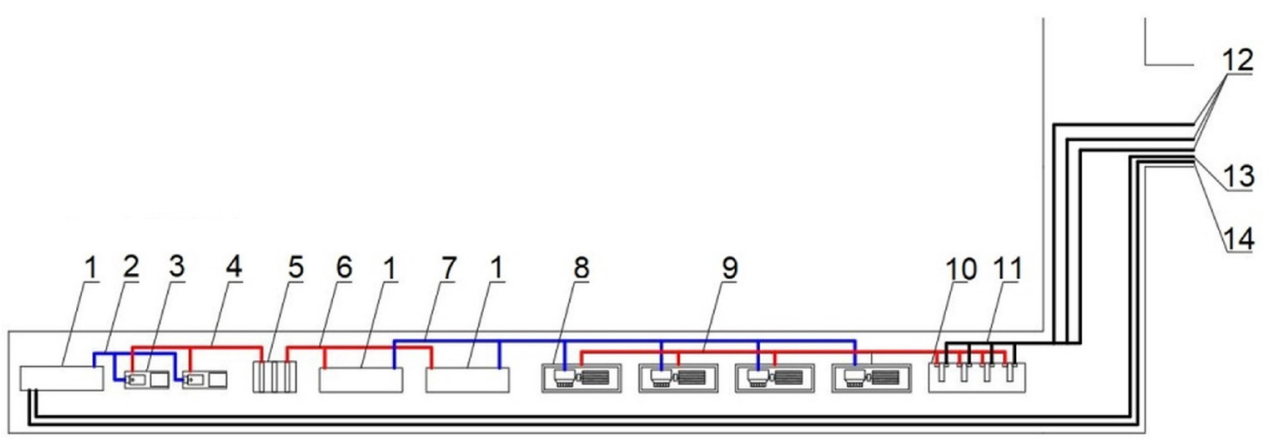

Fig. 1. Concept of arrangement of the equipment included in the pumping station, where: $1-5 \mathrm{~m}^{3}$ emulsion tank, 2 - suction manifold for feeding pumps, 3 - feeding pump, 4 - discharge manifold for low-pressure filter, 5 - low-pressure filter, 6 - collector feeding the filtered emulsion to tanks, 7 high-pressure pump suction manifold, 8 - high-pressure pump, 9 - pressure manifold, 10 - highpressure filter station, 11 - pressure manifold, 12 - pressure pipeline DN80, 13 - emulsion supply pipeline, 14 - drainage pipeline.

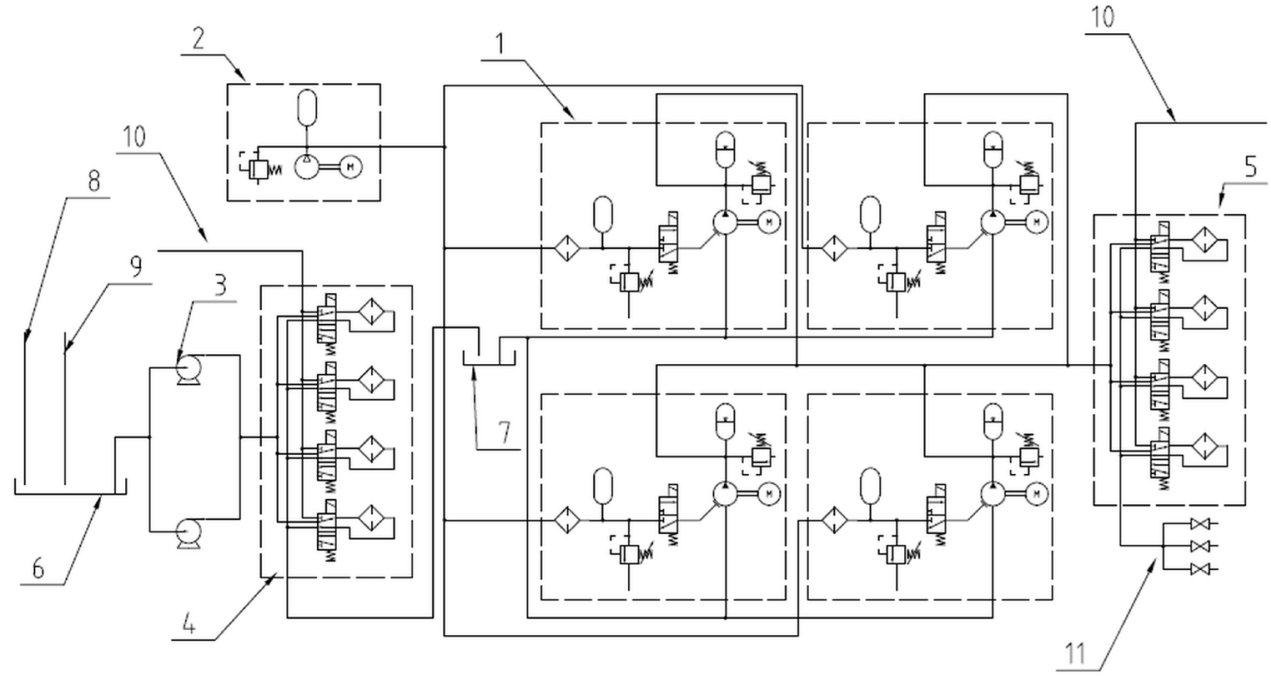

Fig. 2. Schematic diagram of the equipment included in the pumping station, where: 1 - pumping unit, 2 - compressor unit, 3 - centrifugal pump, 4 - low-pressure reversing filters, 5 - high-pressure reversing filters, 6 - pre-tank, 7 - main tank, 8 - emulsion feed, 9 - drain, 10 - run-off of pollutants, 11 - manifolds supplying the emulsion under pressure to individual areas of the mine 


\section{Results}

The total capacity of the pumping units must ensure that it is possible to achieve the planned daily output in each longwall. Determining this performance requires the determination of the absorption capacity of individual types of sections used in a powered roof support and the time needed to be setting it in a new position. Absorption capacity was determined for the types of linear sections of the powered roof support in KWK ROW Chwałowice mine (Fig. 3) in a simplified manner, not taking into account the dynamics of the components and the hydraulic system's capacitance. The required capacity for the hydraulic power units was determined on the basis of the leaks in the hydraulic system and the cylinders in the powered roof support. The analysis of the operating time of the pumps for a shift during which the mining process is halted (longwall shutdown) showed pressure drops caused by leakage in the hydraulic system of the powered roof support. Selected pumps have rigid performance characteristics. Therefore, the volume of liquid that went into the control system was calculated thanks to the measurement of the discharge time. The dependence of volume and time gives the flow rate which is the result of a leak.

The results obtained for the leakage per $1 \mathrm{~m}$ of excavation are as follows:

- for medium walls ( $3 \mathrm{~m}$ high) $0.23 \mathrm{1} / \mathrm{min} / \mathrm{m}$,

- for high walls (4 m high) $0.40 \mathrm{l} / \mathrm{min} / \mathrm{m}$.

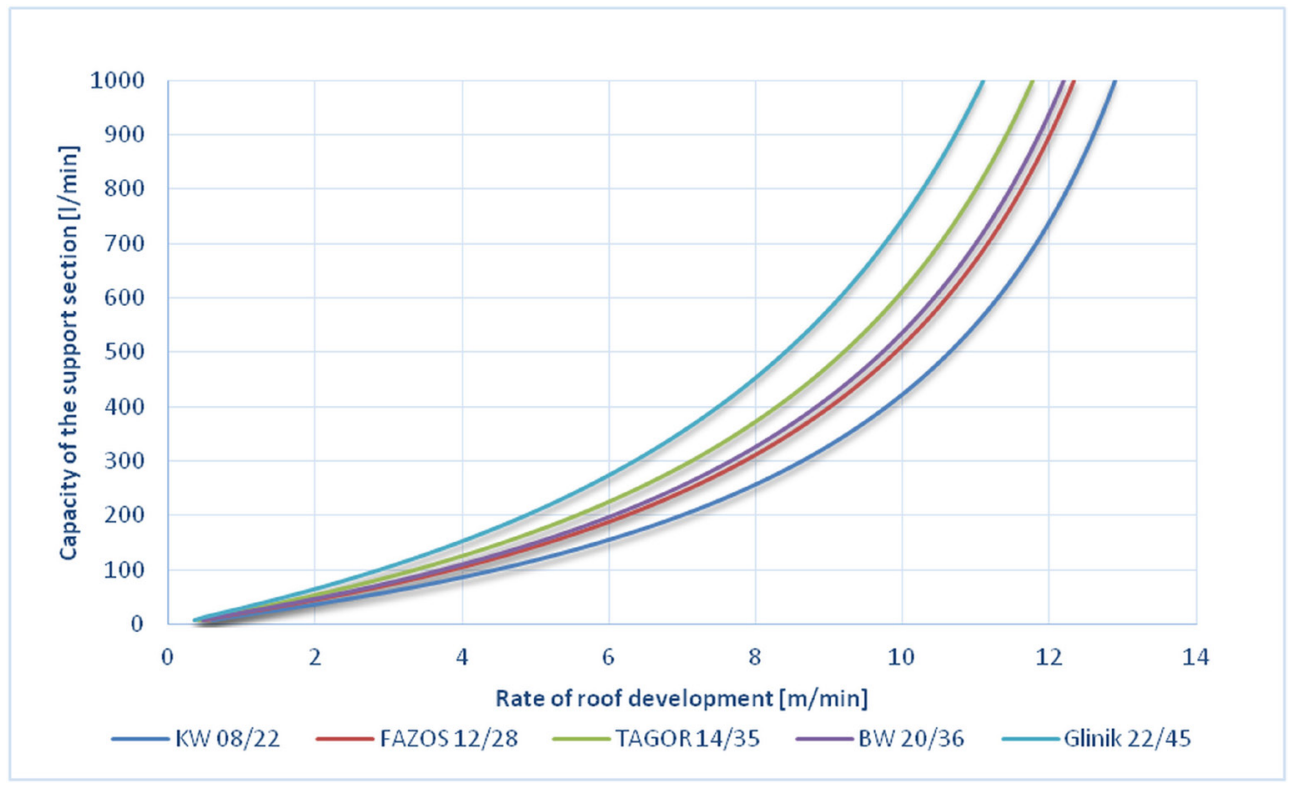

Fig. 3. Absorption capacity for the section of the powered roof support depending on the rate of roof development.

The rate of the roof development should be at least equal to the shearer's movement rate. The required capacity of power generating units in the central hydraulic pumping station was calculated by determining the shearer's movement rate, which enables the planned daily output in individual longwalls to be reached in the future. To estimate this rate, it is necessary to obtain relevant mining and geological data, as well as information about the technical potential and organization of production in a given mine. The required flow rate for the supply of the powered roof support in longwalls for particular months in 2020 was obtained as a result of the analysis and linking the roof installation rate with the 
absorption capacity of the powered roof support section (taking into account leaks in the hydraulic system of the powered roof support). This is presented in Figure 4.

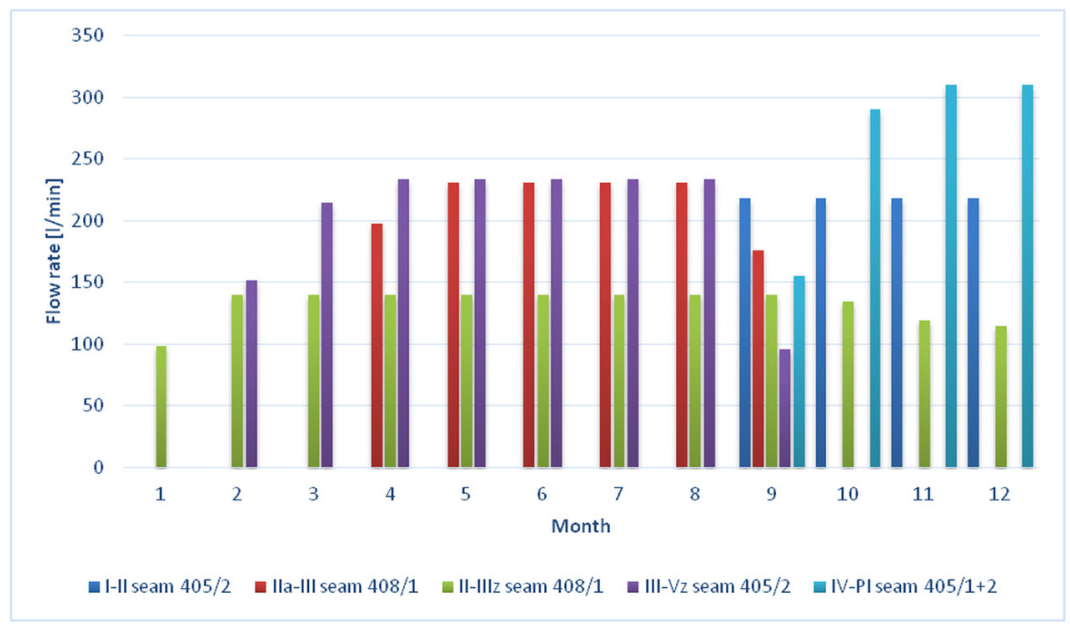

Fig. 4. Required flow rate for individual lngwalls for double-sided mining.

The required flow rate was determined for one-sided (UR1) and two-sided (UR2) mining technologies. The required peak performance was reached in September 2020 and amounted to $820 \mathrm{l} / \mathrm{min}$ for single sided mining. In the case of double-sided mining, 785 1/min was estimated. The diagram (Fig. 5) also shows the maximum required flow rate in the case when the shearer is operating at maximum working speed in each of the longwalls. The required capacity of the central pumping station had to exceed $2500 \mathrm{l} / \mathrm{min}$. The probability of this happening is extremely low. The design of pumping stations and selection of hydraulic power units for the maximum operating parameters of the complexes is not economically justified, as the technical potential of the installed equipment will not be fully utilized.

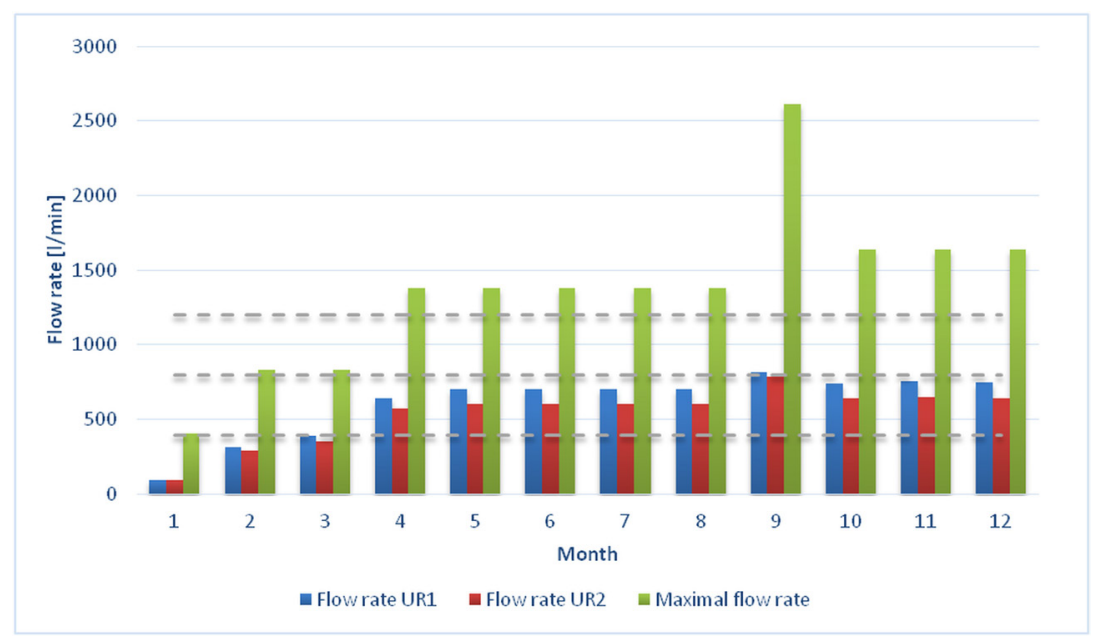

Fig. 5. Total required flow rate for supplying longwall complexes in KWK ROW Ruch Chwałowice 
The design of the central pumping station assumed the installation of four pumping units with a capacity of $401 \mathrm{l} / \mathrm{min}$, which - according to the analysis made - is rational. The analysis assumed that the power supply of the powered roof support in the longwall complex should be provided by two pumping units. Three pumps should be used to maintain a certain reserve capacity. This also enables the interchangeable operation of the hydraulic units. To maintain the reliability of the system, the fourth pump should be in the cold reserve and used in case of failure of one of the other pumping units.

\section{Discussion}

The central pumping station supplying the powered roof support used in the longwall complex was equipped with four pumping units. The capacity of each of them is $401 \mathrm{l} / \mathrm{min}$ and they are driven by $250 \mathrm{~kW}$ electric motors. Selected pumps have a plunger construction, each of them has 5 plungers driven by a crankshaft system. Contrary to popular designs of other manufacturers, pneumatic check valves are the executive element of the control system. This solution is more efficient than using discharge valves in the pump head. The pumps have rigid performance characteristics depending on the discharge pressure. There are also centrifugal pumps, which are used to pre-pressurise the emulsions through a low-pressure filter unit with a filtration accuracy of $100 \mu \mathrm{m}$. The emulsion is also filtered directly before it reaches the pressure manifold in the pressure filter station with a filtration accuracy of $50 \mu \mathrm{m}$. The filters used are cleaned automatically by reversing the liquid stream under pressure. The control of the filter work cycle consists in measuring the pressure drop in this element. When the pressure drop exceeds a preset value, the controller changes the direction of liquid flow through the solenoid valves. The operation of the devices is supervised by a diagnostic system with appropriate controllers. Operating parameters and equipment can be displayed in the control cabin and on computers on the surface with installed software. The equipment included in the central pumping station is shown in Figure 6.

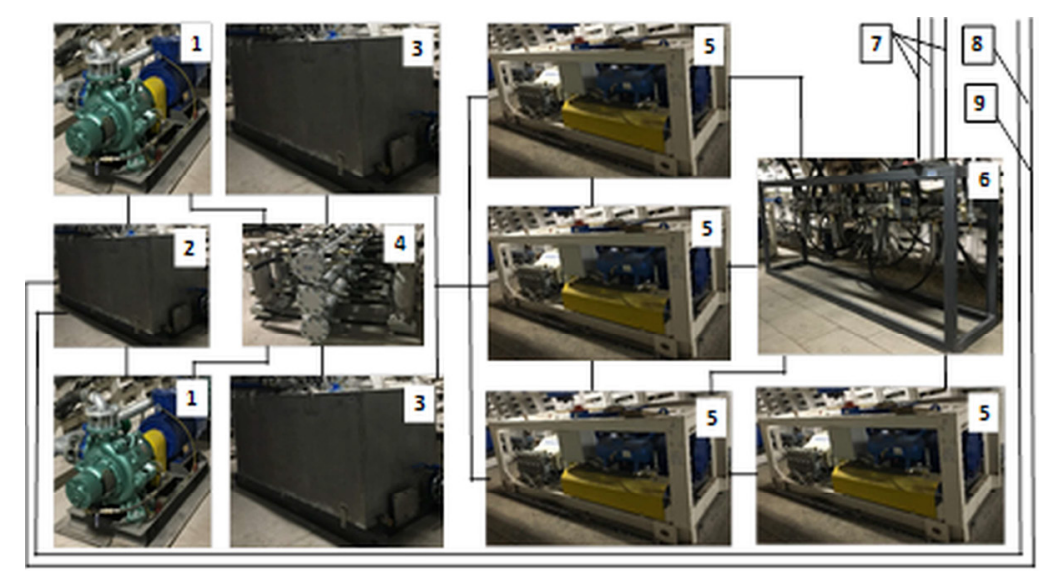

Fig. 6. Equipment built in the central hydraulic pumping station consisting of: 1 - feeding pump, 2 - dirty emulsion tank, 3 - clean emulsion tank, 4 - low-pressure filter, 5 - high-pressure pump, 6 - high-pressure filter station, 7 - pressure pipeline, 8 - emulsion pipeline, 9 - drain pipeline.

The completion of the technical equipment of the central pumping station was preceded by a multi-criteria analysis including:

- the number of longwalls being simultaneously run and their planned daily output,

- the underground infrastructure of the mining plant in terms of hydraulic supply, 
- types of used powered roof support sections.

\section{Conclusion}

The paper presents good practice implemented by Polska Grupa Górnicza S.A. It fits perfectly into the program of Industry 4.0. Thanks to the use of modern machines and equipment and a diagnostic system, the number of stoppages during the operation has been minimized. In the longwalls powered from the central pumping station there was no stoppage caused by pump failures. The presented method of determining the total required capacity of the units in the pumping station allowed to rationally select the number of pumps. The research team used presented analysis to develop requirements and input assumptions which were the foundation of the project. Thanks to the unification of the pump types used, maintenance work is easier. The equipment built in the central pumping station was covered by diagnostics and visualization of work parameters by one trained employee. The central hydraulic pumping station located within short distance brings a number of benefits, including:

- limited the access of dusty air to technical equipment, which has a positive effect on the purity of the oil and water emulsion and limits the degeneration of sealing elements in hydraulic receivers,

- equal quality of the emulsion in all longwalls as it is impossible to add water from fire pipes to the tank at times of increased demand,

- no need to relocate the hydraulic power generating unit and related works in terms of preparing the place of their use,

- the proximity of the workshop where the spare parts are located, which makes all repairs faster,

- continuous monitoring of the pumps by a properly trained operator,

- no possibility of third parties to interfere with the operator's power generating unit.

A joint concept of engineers from KWK ROW Chwałowice mine turned into a project which reulsted in a ready-to-operate innovative central hydraulic pumping station.

\section{References}

1. J. Brodny, M. Tutak, 16th Intern. Multidisci. Scie. SGEM Conf. Proce., 1:2, 299-306 (2016)

2. J. Brodny, M. Tutak, J. of Appli. Fld. Mech., 11:3, 545-553 (2018)

3. M. Cehlár, J. Janocko, Z. Šimková, T. Pavlik, M. Tyulenev, S. Zhironkin, M. Gasanov, Resources, 8 :1, 21 (2019)

4. J. Gil, M. Kołodziej, D. Szurgacz, K. Stoiński, Min. - Info., Autom. and Elect. Engine, 4, 33-38 (2018)

5. S. Zhironkin, M. Gasanov, G. Barysheva, F. Gasanov, O. Zhironkina, G. Kayachev, E3S Web Conf. 21, 04002 (2017)

6. K. Stecuła, J. Brodny, Proc. of 17th Intern. Multidisci. Sci. GeoConf. SGEM, 749-756 (2017)

7. P. Szolc, D. Szurgacz, K. Styrylski, IOP Conf. Series: Mater. Sci. and Engin., 679, 012018 (2019)

8. P. Szolc, Określenie założeń i koncepcja centralnego układu zasilania hydraulicznego w zaktadzie górniczym PGG KWK ROW Ruch Chwałowice (Górnictwa Politechniki Śląskiej, Gliwice, 2019) 
9. Raport 2018 (Górnictwo Węgla Kamiennego w Polsce, Kraków, 2019)

10. D. Szurgacz, New trends in produ. Engin., 1:2, 20-27 (2019)

11. D. Szurgacz, L. Sobik, J. Brodny, Multidisci. Asp.of Prod. Engin., 2:1, 183-190 (2019)

12. D. Szurgacz, L. Sobik, J. Brodny, E3S Web Conf., 105, 01013 (2019)

13. M. Tutak, J. Brodny, Int. J. Environ. Res. Public Health, 16, 1406 (2019)

14. M. Tutak, J. Brodny, Energies, 11:11, 3076 (2018)

15. M. Tutak, J. Brodny, In Proce. of 17th Intern. Multidisci. Sci. GeoConf. SGEM., 635642 (2017) 